\title{
DOMINAÇÃO DE GÊNERO E ESFERA PÚBLICA NA TEORIA CRÍTICA FEMINISTA
}

\section{RURION SOARES MELO ${ }^{1}$}

RESUMO: Pretendemos ressaltar no presente artigo que o ponto de vista de gênero contribui com a atualidade da teoria crítica no que diz respeito à possibilidade de renovação de diagnósticos críticos do tempo presente. Além disso, trata-se de mostrar como os princípios da teoria crítica enriquecidos pela perspectiva de gênero foram empregados em uma crítica imanente do conceito de esfera pública. As feministas entenderam a esfera pública antes como espaço fundamental de uma experiência social em que a dominação cotidiana da mulher e a motivação prática de resistência e luta precisam ser investigadas de dentro das próprias formas de interação que compõem a vida cotidiana da sociedade.

PALAVRAS-CHAVE: teoria crítica; feminismo; esfera pública; dominação social.

ABSTRACT: We intend to emphasize in the present article that the gender point of view contributes with the actuality of critical theory regarding the possibility of renewal of critical diagnoses of the present time. Moreover, it is a question of showing how the principles of critical theory enriched by the gender perspective were employed in an immanent critique of the concept of the public sphere. Instead, feminists have understood the public sphere as a fundamental space of a social experience in which the daily domination of women and the practical motivation of resistance and struggle need to be investigated from within the forms of interaction that constitute the daily life of society.

KEYWORDS: critical theory; feminism; public sphere; social domination.

O feminismo faz parte decisivamente das preocupações da teoria e da práxis política nas sociedades contemporâneas. O projeto mesmo de uma vida democrática requer superar toda sorte de desrespeito, discriminação e violência contra as mulheres, isto é, toda assimetria que produz socialmente dominação de gênero. Suas preocupações têm implicações sobre a totalidade da sociedade. Não há tema da teoria política e da teoria social que não tivesse de passar pelo crivo da crítica feminista: representação política, esfera pública e esfera privada, 
direitos e cidadania, autonomia e autorrealização, igualdade e diferença, movimentos sociais, costumes e cultura política. Trata-se de uma projeção radicalmente democrática de uma sociedade justa, livre e igual que expande o conceito do político para todas as práticas sociais da vida cotidiana ${ }^{2}$.

Pretendo me concentrar na maneira como a tradição de pensamento conhecida como "teoria crítica" incorporou algumas das questões relacionadas à dominação de gênero. Na primeira parte do artigo, pretendo ressaltar que o ponto de vista de "gênero" contribui com a própria atualidade da teoria crítica no que diz respeito à possibilidade de renovação de diagnósticos críticos do tempo presente (I). Neste caso, a teoria crítica feminista lança luz tanto sobre os bloqueios à emancipação quanto sobre as novas gramáticas das lutas sociais e políticas em curso. Na segunda parte, mostro como os princípios da teoria crítica enriquecidos pela perspectiva de gênero foram empregados em uma crítica imanente do conceito de esfera pública (II). Este conceito, que é central na disputa pela radicalização da democracia, passou então a ser compreendido não apenas do ponto de vista do entrave criado pelo sistema político a conquistas para a cidadania e para a institucionalização democrática. A perspectiva de gênero entendeu a esfera pública antes como espaço fundamental de uma experiência social em que a dominação sobre a mulher e a motivação prática de resistência e luta precisam ser investigadas de dentro das próprias formas de interação que compõem a vida cotidiana da sociedade.

\section{I}

Quando Max Horkheimer escreve seu célebre artigo "Teoria tradicional e teoria crítica”, publicado originalmente em 1937, foram estabelecidos critérios extremamente exigentes para que possamos entender o que significa uma teoria que porta uma atitude crítica diante da sociedade: o ponto de vista crítico da teoria precisaria ser produzido de maneira imanente, isto é, de dentro dos próprios processos sociais historicamente existentes (HORKHEIMER, 2009). Desde o início, portanto, uma teoria crítica da sociedade deveria justificar o ponto de vista normativo pressuposto em sua própria crítica sem lançar mão simplesmente de critérios ideais e deontológicos que fossem independentes de um diagnóstico dos bloqueios existentes e dos potenciais emancipatórios socialmente enraizados. Esse modo de proceder da teoria crítica está estreitamente vinculado à necessidade de um exame inicial, 
mas aprofundado, dos processos e desenvolvimentos históricos concretos, a partir dos quais seja possível à teoria simultaneamente diagnosticar os bloqueios do tempo presente e compreender o sentido das ações existentes capazes de iluminar orientações igualmente concretas para a emancipação (NOBRE, 2004).

A junção desses dois aspectos assinalados - diagnóstico de patologias sociais e orientação para a emancipação com base nas possibilidades existentes de resistência e luta criaram um procedimento aberto e dinâmico no desenvolvimento da história da teoria crítica. De um lado, as categorias centrais utilizadas nesta tradição de pensamento não podem ser anistóricas, já que sempre possuem uma gênese em diferentes contextos de surgimento. De outro lado, cria-se uma exigência interna aos próprios teóricos críticos de testar constantemente seus diagnósticos e conceitos apresentados: a renovação dos diagnósticos críticos é necessária para avaliar a atualidade da teoria enquanto tal. Por esta razão, a existência mesma da teoria crítica se deve a seu potencial de renovação, à capacidade de relacionar de maneira imanente teoria e práxis e demonstrar a força de suas categorias com base nos processos sociais existentes. E tal renovação terá impacto decisivo em relação às duas dimensões que formam os diagnósticos do presente: trata-se tanto de compreender que as causas sociais da dominação variam historicamente quanto diagnosticar a mudança nos sentidos da emancipação (MELO, 2013).

A história ampla da teoria crítica, de Marx aos dias atuais, desdobra-se de acordo com seus momentos de renovação, permitindo caracterizar também um rico pluralismo na diversidade de seus autores e modelos: capitalismo desenvolvido e luta de classes, capitalismo de Estado e reificação, Estado social e as ambiguidades da política, Estado de direito e a democratização de suas instituições, novos movimentos sociais e as lutas por reconhecimento, etc. (NOBRE, 2008). Os diagnósticos mostram que dominação e emancipação são constituídas por fatores múltiplos (economia, cultura, política), relacionam-se de modo variado com os portadores da emancipação (proletariado, estudantes, negros, mulheres, minorias multiculturais) e precisam ser investigadas com base em um arranjo interdisciplinar das pesquisas sociais (sociologia, economia, filosofia, direito, psicanálise).

Ora, a teoria crítica vinculada às questões feministas (refiro-me neste artigo principalmente a Iris Young, Nancy Fraser e Seyla Benhabib, ainda que suas abordagens não se limitem, de modo algum, ao "feminismo") pretende justamente disputar diagnósticos mais adequados em relação às formas de dominação existentes e às respectivas lutas envolvidas 
nestes diagnósticos ${ }^{3}$. Ela incorpora a reconstrução da história política e social também do ponto de vista da subordinação das mulheres para mostrar, ao mesmo tempo, que não há história da dominação adequadamente diagnosticada que possa permanecer cega em relação a gênero e, além disso, fazer uma crítica dos modelos críticos até então vigentes na medida em que identifica a cegueira de gênero que os acompanhou. Embora exista uma postura ativista por parte das autoras da teoria crítica que as motive a ressaltar uma temática feminista em seus trabalhos, estas autoras também se preocupam com a dominação de gênero a partir de uma intenção teórica partilhada em comum por todos aqueles que buscam produzir diagnósticos mais enriquecidos do tempo presente e, assim, fundamentar adequadamente o ponto de vista crítico-normativo de suas abordagens.

Por serem consequentes com os princípios mencionados da teoria crítica, a construção conceitual procura evitar especulações idealizantes e metateóricas, voltando-se, pelo contrário, às mediações responsáveis pelo enraizamento social do diagnóstico crítico, à relação entre teoria e práxis e à gênese mais concreta dos critérios normativos. $\mathrm{O}$ ponto de partida, portanto, são contextos sociais em que são observadas formas de poder socialmente geradas. Como diz Young, a teoria crítica não deve partir simplesmente de um ideal de justiça, mas sempre dos "conceitos de opressão e dominação" que estruturam as relações sociais (YOUNG, 1990, p. 3). Problemas de gênero entram em cena para que a teoria não produza conceitos parciais em seu diagnóstico de tais relações. Exclusão política e jurídica, violência doméstica, divisão de trabalho, discriminação social e cultural, são manifestações de poder social que possuem lógicas próprias ainda que cruzadas. A perspectiva da desigualdade econômica permite avaliar o impacto negativo da opressão de classe, da injustiça material e do desrespeito social, porém também o gênero lança muita luz sobre as condições particulares de opressão causadas pela economia ou ainda pelas instituições políticas, as quais são vividas neste viés tão somente pelas mulheres. Um enraizamento social adequado implicaria então uma teoria sensível às condições da mulher interseccionadas entre gênero, classe, raça e sexualidade ${ }^{4}$. Nesse sentido, podemos apontar limites nos diagnósticos de fundo de modelos críticos, enriquecendo-os com o viés de gênero ${ }^{5}$.

A subordinação das mulheres deve poder ser reconstruída de tal forma que a teoria possa considerar sempre o enraizamento de suas categorias da perspectiva das próprias afetadas. Com isto, a teoria crítica feminista segue o princípio de nunca fazer com que a teoria (detentora de potencial reflexivo) tenha primado diante da práxis dos próprios sujeitos. Fraser 
seguiu explicitamente este princípio em seus primeiros escritos, definindo a teoria crítica (junto com Marx) como o "auto-esclarecimento das lutas e desejos de uma época" (FRASER, 1989, p. 113). É verdade que a identificação com o movimento social do tempo presente (e a autora se refere especialmente ao movimento feminista) não deve ocorrer, ressalta a autora, de modo "acrítico". Mas sempre a teoria crítica deve procurar acompanhar as aspirações, interesses e necessidades dos grupos oprimidos, já que "as questões que ela responde e os modelos desenhados são informados por esta identificação e por estes interesses" (Idem, p. 113). Também Young, talvez de maneira ainda mais radical do que Fraser, traduziu o enraizamento social de sua teoria crítica identificando-o com a constituição e as demandas dos movimentos sociais (YOUNG, 1990). Esta identificação requer sempre uma preocupação com os sujeitos da emancipação, suas diferentes experiências negativas de sofrimento e sujeição, e com suas próprias capacidades de superação prática. Adotar a perspectiva das mulheres significa produzir uma teoria que compreenda e exponha as causas e processos que levam à subordinação de gênero, isto é, que não omita as relações sociais baseadas na dominação masculina, e que possa justificar seu propósito emancipatório com base na situação política e nas lutas do movimento feminista.

Por fim, quando se procura fundamentar o ponto de vista da crítica, surge uma tensão necessária entre a mera afirmação do existente e o horizonte normativo ao qual a teoria aspira (sem que esta aspiração, como acabamos de ver, seja apenas da teoria, pois precisa estar ancorada nos interesses práticos e necessidades dos próprios concernidos). Segundo Young, os critérios normativos devem ser fundamentados tendo em vista os problemas seguintes:

A Teoria Crítica rejeita como ilusórios os esforços para se construir um sistema normativo universal isolado de uma sociedade particular [...] Refletindo de dentro de um contexto social particular, a boa teorização normativa não pode evitar descrições e explanações político-sociais. Sem teoria social, a reflexão normativa é abstrata, vazia e incapaz de guiar a crítica com o interesse prático na emancipação. Entretanto, diferentemente da teoria social positivista, que separa fatos sociais de valores e reclama a pretensão de neutralidade, a Teoria Crítica nega que a teoria social deva aceitar o existente. A descrição e o esclarecimento social devem ser críticos, isto é, visar à avaliação do existente em termos normativos. Sem essa postura crítica, não serão respondidas muitas questões sobre o que ocorre em uma sociedade e por que, a quem beneficia e quem é prejudicado, sendo a teoria responsável por reafirmar e reificar a realidade social existente (YOUNG, 1990, p. 5).

Critérios normativos imanentes, portanto, não repõem simplesmente a força do existente, uma vez que a exigência teórica de "enraizamento" não deve se confundir com positivismo. Em outros termos, o positivismo não é o avesso de normativismo abstrato. A solução da teoria crítica é encontrar uma mediação adequada, de modo que o normativo tenha 
gênese na concretude e na negatividade de experiências sociais existentes. E o impacto sobre o procedimento de fundamentação é bastante complexo na medida em que supõe algum distanciamento reflexivo do teórico não somente em relação ao poder vigente (dos imperativos econômicos, do Estado, de grupos de opressão), mas também diante dos próprios movimentos sociais insurgentes. Com praticamente todos os autores da teoria crítica ocorreu tal distanciamento. A teoria crítica, por não poder ser compreendida como mero reflexo dos interesses imediatos dos grupos sociais em disputa, precisa evitar simplesmente replicar a voz do movimento social. As autoras e autores divergem quanto a tal distanciamento e ao peso que os critérios normativos têm em cada modelo crítico, mas sempre há uma preocupação em encontrar um equilíbrio entre o ponto de vista normativo da teoria e as aspirações que motivam a práxis política dos sujeitos.

Benhabib difere levemente das posições iniciais de Young e Fraser a respeito do equilíbrio entre teoria e práxis. Vimos que ambas as autoras tentaram vincular de maneira mais estreita o propósito da teoria com as aspirações e demandas dos movimentos sociais ${ }^{6}$. Já para Benhabib

uma teoria normativa, em particular uma teoria social crítica, não pode assumir sem mais as aspirações de quaisquer atores sociais e fazer com que seu critério crítico se adapte às demandas de um movimento social particular. O comprometimento com a transformação social, ainda assim com um certo distanciamento crítico, mesmo que seja a partir das demandas daquelas com quem nos identificamos, é essencial à vocação do teórico na qualidade de crítico social (BENHABIB, 1992a, p. 109-110)

Portanto, a despeito de suas diferenças, a preocupação comum com uma crítica normativa que não permaneça descolada das interações e contextos sociais marca decisivamente as abordagens das autoras cujas teorias têm sido vinculadas aos temas do feminismo. Princípios normativos não devem poder se tornar insensíveis às particularidades e concretudes das práticas sociais. Isso implica incluir em tal enraizamento não somente fenômenos da vida social como um todo em que a subordinação e a heteronomia se generalizem como padrão de dominação de gênero (família, escola, igreja, universidade, trabalho, espaços intermediários de socialização), mas também encontrar nas interações ordinárias critérios crítico-normativos enraizados nas disposições à solidariedade, ao reconhecimento mútuo, respeito e dignidade iguais entre as pessoas (BENHABIB, 1992b). E 
é precisamente no intuito de pensar a política pela incorporação de todas as práticas sociais da vida cotidiana que o conceito de esfera pública foi absorvido pela teoria crítica feminista.

\section{II}

Correndo o risco de ser excessivamente esquemático, talvez possamos distinguir dois planos de análise das autoras no que concerne ao conceito de esfera pública. O primeiro deles é mais empírico-descritivo, vinculado sobretudo à reconstrução histórica e institucional da dominação de gênero. O segundo é o crítico-normativo, porque se volta principalmente à reconstrução dos pressupostos conceituais e dos ideais morais das teorias da esfera pública. Nas três autoras encontramos ambos os planos de análise, mas podemos afirmar que Young se aproxima mais do primeiro e Benhabib, do segundo, ao passo que Fraser procura transitar constantemente entre os dois. Outro traço comum diz respeito ao fato de que elas partem igualmente do livro Mudança estrutural da esfera pública, de Jürgen Habermas (publicado originalmente em 1962), tanto para reconsiderar a limitação histórica do conceito quanto para repensar seus pressupostos normativos. Uma rápida olhada na tese geral deste livro e nas críticas que lhe foram endereçadas pelos historiadores servirá para entender sinteticamente o que estava em jogo em termos empírico-descritivos. Logo em seguida, voltaremos já para o plano crítico-normativo, onde concentrarei a maior parte da exposição restante.

Como indica o subtítulo de seu livro, o intuito de Habermas foi elaborar uma investigação das tendências históricas da esfera pública como uma categoria burguesa, do século XVII até meados do século XX na Inglaterra, França e Alemanha. Ele expõe seu surgimento no contexto liberal junto à formação de um "público de pessoas privadas que discutem mediante razões" (HABERMAS, 2014, p. 91), investigando suas transformações posteriores no quadro do Estado de bem-estar social. Sua finalidade não é apenas a da descrição histórica (ainda que a grande totalidade do livro esteja baseada na reconstrução histórica), mas também mostrar de onde surgiram os ideais burgueses emancipatórios atrelados à ideia de democracia como autodeterminação e autogoverno político de cidadãos livres e iguais (Idem, § 13). Além disso, a tese central do livro não consiste na apresentação e defesa desses critérios normativos de inclusão e igualdade cidadãs que a esfera pública representa, mas acima de tudo mostrar sua decadência nas condições das democracias de massa e do Estado de bem-estar. O livro foi escrito sob o paradigma da crítica da ideologia, e é precisamente o próprio conceito de esfera pública que é denunciado por Habermas quando passa a conter um uso ideológico nas condições de classe do capitalismo contemporâneo. 
Dada a importância do livro de Habermas e todos os seus desdobramentos (inclusive no interior do desenvolvimento de sua própria teoria), limito-me aqui a indicar os principais pontos de desacordo em torno da reconstituição histórica apresentada, reservando atenção sobretudo à questão de gênero ${ }^{7}$. Em geral, tais críticas sublinham pressupostos históricos insuficientes porque parciais, uma vez que Habermas teria reduzido o conceito à realidade da sociedade civil burguesa em um período de tempo muito determinado. Com isto, muitos acabariam sendo "excluídos" da reconstrução da esfera pública "burguesa" apresentada, como o próprio Habermas reconhece em seu Prefácio de 1990 (HABERMAS, 2014, p. 45-49). Aquela não seria, por exemplo, a história do proletariado no mesmo período (KLUGE e NEGT, 1993; CALHOUN, 1982) e também não uma esfera pública sensível à dominação de gênero.

A primeira e talvez mais significativa reconstrução histórica alternativa da literatura feminista, evidentemente não cega aos problemas de gênero, veio com o livro de Joan Landes $(1988)^{8}$, que tratou do caráter patriarcal de nossa esfera pública, o qual foi negligenciado na clássica abordagem de Habermas. Landes mostra com o rigor de uma grande historiadora os impactos institucionais e culturais de uma esfera pública formada por um público leitor constituído também de mulheres, mas por isto mesmo prenhe de hierarquias e desigualdades. Landes abre dois tipos de caminho no debate sobre o conceito de esfera pública. Primeiramente, incentiva pesquisas sociais que incorporam empiricamente outros contextos históricos, sociais e políticos sobre as mulheres na vida política, sempre com ênfase no conceito de esfera pública como arena ${ }^{9}$. Além disso, introduz um dos principais eixos no debate sobre os aspectos crítico-normativos: o conceito de esfera pública não pode ser empregado de maneira crítica caso deixe intacta a estrutura patriarcal que lhe é inerente, explicitando que os ideais da democracia burguesa contradizem certamente seus pressupostos essenciais de autocompreensão, baseados na universalidade, na igualdade e na autonomia de todos os cidadãos.

É inegável que para a teoria crítica feminista o diagnóstico em torno da subordinação das mulheres precisa incluir em seu escopo uma compreensão adequada sobre a esfera pública. Será na e pela esfera pública que tanto se materializam as experiências difusas, mais ou menos explícitas, de dominação de gênero quanto são desencadeadas as lutas feministas pela democratização da vida política nas sociedades contemporâneas. Eu gostaria de tratar do conceito levando em consideração quatro conjuntos temáticos: a distinção entre esfera privada 
e esfera pública (a), o primado do justo sobre o bem que lhe é correlato (b), a dimensão inclusiva e porosa da performance e das tematizações (c) e os aspectos formais e informais que compõem todo o processo de formação de poder de uma multiplicidade de públicos e contra-públicos (d). Todos eles em conjunto procuram mostrar o tipo de preocupação que essas teóricas têm em tratar a esfera pública como um espaço social por definição, com mediações entre a sociedade civil e o sistema político, mas fundamentalmente reconstruído pelos conflitos e práticas sociais ${ }^{10}$.

(a) Uma das contribuições mais importantes do feminismo consistiu em questionar os argumentos que tradicionalmente justificam a distinção entre esfera privada e esfera pública. Tal distinção se baseou historicamente em instituições da sociedade civil e da cultura pública "sexista" em que ideais de participação e cidadania eram atribuídos exclusivamente aos homens (FRASER, 1997b). À figura masculina se atribuiu a racionalidade, a propriedade, a cidadania, como se os homens portassem virtudes mais naturalmente vinculadas à universalidade e à justiça. Assembleias, parlamentos e associações civis de formação pública da opinião e da vontade seriam espaços concernentes não às mulheres, mas tão somente aos homens. Ao passo que as mulheres deveriam se limitar a seu lugar "natural" na esfera privada doméstica, assumindo os papeis sociais de mãe e esposa ${ }^{11}$. Portanto, as mulheres se submeteram historicamente a uma dominação estrutural em um duplo sentido: foram excluídas dos direitos iguais de cidadania e das práticas concretas de participação da vida política, mas também se mantiveram subordinadas a uma função meramente doméstica em que o homem, na qualidade de marido e pai, possui o poder não apenas simbólico mas sobretudo financeiro sobre a mulher.

A "privacidade" da esfera privada, portanto, acaba produzindo efeitos colaterais e patológicos na medida em que confina historicamente a mulher em um círculo de dominação naturalizada em determinadas atividades privadas: cuidar dos filhos, cuidar da casa, satisfazer o marido tanto emocional quanto sexualmente, etc. E o fato de tais atividades fazerem parte da esfera privada impossibilita que este espaço social seja racionalmente questionado com base em critérios críticos de igualdade e justiça, que sempre são reivindicados enquanto normas que regem a vida pública. Como lembra Benhabib, "as normas da liberdade, equidade e reciprocidade pararam diante da porta de entrada da casa" (1992, p. 13). Ou seja, se as mulheres apenas com muito custo adentraram a esfera pública, também a divisão de trabalho baseada no gênero continua, na esfera privada, não sendo objeto de discussão moral e política. 
Por esta razão, é agenda da luta feminina a politização do domínio privado, ou seja, impedir que a subordinação das mulheres nesta divisão naturalizada de trabalho seja deixada fora do debate público. Esta politização implica, portanto, tematizar publicamente - no sentido de tornar o social algo político - as experiências das mulheres na vida doméstica em particular, mas, além disso, democratizar as relações privadas (envolvendo sexualidade, relação com o corpo, padrões familiares, etc.).

Por isto, para as feministas não é possível simplesmente separar vida pública da vida privada. "Como ocorreu com todo movimento de libertação", de acordo com Benhabib,

o movimento contemporâneo das mulheres está tornando o que até hoje foi considerado tema "privado" da vida boa questões "públicas" de justiça ao tematizar as relações assimétricas de poder sobre as quais a divisão sexual do trabalho entre os gêneros se apoiou. Neste processo, a linha entre o privado e o público, entre questões de justiça e temas da vida boa, está sendo renegociada" (BENHABIB, 1992a, p. 109).

A autonomia das mulheres depende assim da renegociação, ou seja, da politização dos critérios vigentes que regem a vida privada. Existe um entrelaçamento entre tais âmbitos, na medida em que a própria disputa na esfera pública (por direitos, por participação política) avançaria em termos emancipatórios junto à efetivação cada vez maior da liberdade e da autonomia em outros domínios das interações sociais. Uma sociedade digna de ser considerada democrática aos olhos dos próprios participantes precisa modificar os padrões de autoridade e poder que impossibilitam que as mulheres exerçam uma autonomia socialmente enraizada, isto é, que possam se autogovernar, sendo reconhecidas e respeitadas em seus modos de vida (MELO, 2017).

(b) A separação entre privado e público pressupõe uma outra distinção normativa igualmente relevante, a saber, aquela do primado da justiça sobre o bem. Sempre se associou as questões de justiça com as "normas" da esfera pública, ao passo que somente o âmbito privado permitiria incluir temas ligados à vida boa, isto é, aos valores e visões de mundo pessoais. O efeito desta distinção é duplo. De um lado, influindo diretamente na naturalização da distinção entre privado e público, ela corrobora a despolitização de temas relativos ao bem, à intimidade e às relações primárias concretas, uma vez que "a esfera pública, a esfera da justiça, caminha para a historicidade, enquanto a esfera privada, a esfera do cuidado e da intimidade, é imutável e atemporal” (BENHABIB, 1992b, p. 157). O “domínio atemporal do lar" reduz assim experiências afetivas primárias (amor, amizade e cuidado) a aspectos 
apolíticos, porque não morais nem passíveis de discussão, em que vínculos, sentimentos, necessidades e compartilhamentos não poderiam ultrapassar o âmbito dos valores pessoais restritos ao espaço pessoal ou doméstico.

De outro lado, uma vez renegociada a hierarquia entre o justo e o bem, também a esfera pública precisa se democratizar para poder incluir em seu domínio valores e visões de mundo relativas à vida boa. Benhabib pretende trazer para a dimensão cotidiana da política pontos de vista também concernentes ao "outro concreto", permitindo que direitos, deveres e normas morais possam conviver com considerações a respeito da história concreta, identidade, afetos e modos de vida de cada um de nós (BENHABIB, 1992b). O debate público, portanto, precisa ser interpretado de maneira radicalmente inclusivo, deixando que temas e valores da moralidade própria das interações cotidianas circule entre os domínios privados e público. O bloqueio ou a cristalização da hierarquia entre justiça e bem produz submissão, exclusão e heteronomia não apenas para as mulheres. Representaria o enfraquecimento da democracia, na medida em que a esfera pública, cuja fronteira foi decidida de antemão, fecha-se para o reconhecimento da identidade moral do outro concreto. Por isso a defesa incondicional de um "procedimentalismo radical" na teoria democrática (BENHABIB, 1992a, 2007), em que todas as experiências pessoais de dominação e todas as aspirações emancipatórias dos novos movimentos sociais podem ser igualmente discutidas, aberta e publicamente, entre todos os concernidos e participantes:

O modelo discursivo, precisamente porque procede de uma norma fundamental de reciprocidade igualitária e precisamente porque projeta a democratização de todas as normas sociais, não pode evitar a democratização das normas familiais e das normas que governam a divisão de trabalho baseada no gênero dentro da família também. Se nos discursos a agenda de conversação é radicalmente aberta, se os participantes podem trazer todo e qualquer assunto ao escrutínio e ao questionamento públicos, então não há como predefinir a natureza das questões discutidas como sendo as públicas da justiça versus as privadas da vida boa. Distinções tais como a entre justiça e vida boa, entre normas e valores, interesses e necessidades são "subsequentes" e não anteriores ao processo de formação discursiva da vontade (BENHABIB, 1992a, p. 110).

A luta das mulheres passa então por um desbloqueio da agenda pública de discussão, envolvendo divisão de trabalho doméstico, educação dos filhos, relação com a sexualidade e o corpo, sem que de antemão se decida sobre o caráter normativo de tais práticas e experiências sociais. O feminismo radicaliza assim a possibilidade moderna da autonomia e da autodeterminação, lutando pela negociação radical de todas as normas sociais vigentes, por uma apropriação crítica da tradição e pela formação reflexiva de autoidentidades e histórias de vida. 
(c) Embora a esfera pública não se reduza à deliberação e ao discurso, pois é também um espaço social conflituoso, pré-reflexivo e ambíguo, as práticas discursivas e de comunicação pública acabam produzindo e reproduzindo hierarquias indesejadas de gênero. Concepções liberais ou republicanas de democracia demandam critérios rígidos, mas pretensamente neutros, de participação política, cujo efeito pode ser o de excluir, silenciar e desvalorizar determinadas pessoas e grupos. Do ponto de vista do diagnóstico geral, as instituições democráticas do Ocidente têm sido

elitistas e exclusivistas, e essas exclusões marcam suas concepções de razão e deliberação [...] Desde seus princípios iluministas, têm sido instituições dominadas pelo sexo masculino e, em sociedades diferenciadas por classes e raças, têm sido dominadas pela raça branca e pela classe mais privilegiada. Apesar de se afirmar a capacidade de formas deliberativas de produzir reuniões ordenadas para expressar a razão universal pura, as normas de deliberação são culturalmente específicas e frequentemente operam como formas de poder que silenciam ou desvalorizam o discurso de alguns (YOUNG, 2001, p. 370).

Um modelo mais inclusivo de comunicação política deveria reverter os efeitos colaterais do ideal democrático clássico, o qual seria mais poroso à posição social, à diversidade cultural e a práticas sensíveis a uma multiplicidade de experiências. A esfera pública é constituída não apenas por discursos formais, racionais e "desapaixonados", mas também mediante emoção, afetos e corpo. Simbolicamente, o corpo tem sido carregado de significação política nas tematizações e performances dos movimentos sociais antirracistas, LGBT's e feministas. Trata-se de defender assim uma concepção democrática de esfera pública que possa incluir "um conceito mais amplo das formas de estilos de discurso que envolvem a discussão pública” (Idem, p. 373). Neste caso, as tematizações apelam para variedades de pontos de vista e pressupõem a diversidade na vida pública, com perspectivas, interesses, valores e significados culturais diferentes. Permitem também produzir um processo de compartilhamento no espaço público das narrativas ligadas às experiências de injustiça e dominação vividas diferentemente pelas pessoas.

(d) Já mostramos que a concepção habermasiana de esfera pública exposta no conhecido livro de 1962 não inclui em sua reconstrução histórica públicos "concorrentes", isto é, que não sejam liberais, burgueses e homens. Contudo, a história da esfera pública oficial, com seu modo hegemônico de dominação, foi acompanhada pela história alternativa de públicos concorrentes, chamados por Nancy Fraser de "contra-públicos". Estes representam concepções alternativas da reconstrução histórica e normativa do conceito de esfera pública, dentre as quais aquelas que se debruçaram sobre a compreensão das experiências sociais e formas de organização política das mulheres. Além da possibilidade de 
uma história alternativa, eles constituem públicos que concorrem em termos práticos, isto é, formam contra-poderes, ainda que minoritários, diante do poder vigente. Por isto, as relações entre os públicos burgueses e os outros públicos sempre foram conflituosas. Desde sempre, afirma Fraser, "os contra-públicos contestaram as normas exclusivistas do público burguês, elaborando estilos alternativos de comportamento político e normas alternativas de discurso público" (1997b, p. 75).

As feministas estão preocupadas em diagnosticar uma esfera pública que acomode a dinâmica dos conflitos sociais, incluindo condições de confronto e possíveis negociações entre públicos múltiplos e que estejam de acordo com sociedades estratificadas e multiculturais. Os "contra-públicos" são formados geralmente por aqueles em situação de poder desfavorável e subordinada. Membros de grupos subordinados somente com grande dificuldade encontram voz no espaço público e tematizam seus problemas, necessidades e aspirações:

Membros de grupos sociais subordinados - mulheres, trabalhadores, pessoas de cor, gays e lésbicas - sempre acharam vantajoso constituir públicos alternativos. Proponho chamar estes últimos de contra-públicos subalternos com a finalidade de sinalizar que são arenas discursivas paralelas onde membros de grupos sociais subordinados inventam e circulam contra-discursos para formular interpretações opostas de suas identidades, interesses e necessidades (Idem, p. 81).

Outro ponto importante a ser considerado é a configuração complexa, tanto formal quanto informal, da esfera pública como espaço de circulação do poder $^{12}$. Das experiências cotidianas de desrespeito e subordinação até as formas organizadas de participação política e influência sobre as instituições, a esfera pública conta com dimensões intermediárias da sociedade civil fundamentais na elaboração de suas práticas sociais. Os "contra-públicos subalternos", na maior parte das vezes constituídos de maneira plural e fragmentada, podem obter, em situações de crise e conflito, força o suficiente para influenciar a opinião pública (com as grandes mídias, mas também com as mídias alternativas) e, em alguns casos, influenciar processos de institucionalização. Segundo Fraser, não estamos apenas diante de um uso público da razão cristalizado formalmente no sistema político (nos Parlamentos ou no Judiciário, por exemplo). Os contra-públicos são socialmente capazes de exercer pressão de maneira horizontal e informal no processo amplo de formação da opinião em universidades, associações civis, escolas, ou outros espaços de encontro cotidiano, e valendo-se de meios culturais diversos (jornais, revistas, televisão, rádio, internet, eventos, encontros informais) (Fraser, 1997b). 
Também Benhabib está interessada em compreender os espaços de formação da opinião em que estão publicamente enraizadas as exigências normativas de autonomia e pluralismo. A esfera pública não é de fato constituída de um público homogêneo. Pelo contrário, os movimentos sociais têm investido na pluralidade dos modos de associação. Por conseguinte, a disputa política emancipatória passa a girar em torno de uma concepção de esfera pública em que os pontos de vista das minorias, dos menos favorecidos e das diferenças possam ser publicamente reconhecidos:

É por meio de uma rede interligada dessas múltiplas formas de associações, redes, e organizações que uma "comunicação pública" anônima surge. Para o modelo deliberativo de democracia é fundamental que se privilegie essa esfera pública de redes justapostas e mutuamente entrelaçadas, e as associações de deliberação, contestação e argumentação. [...] hoje, nosso modelo guia tem de ser aquele de um medium de focos múltiplos e livremente associados de formação e disseminação de opiniões, que afetam um ao outro num processo de comunicação espontânea e livre (BENHABIB, 2007, p. 58, grifos da autora).

Estes aspectos do conceito de esfera pública considerados em conjunto produzem uma imagem mais ampla e enriquecida dos diagnósticos a respeito da dominação de gênero e das possibilidades socialmente existentes de resistência e motivação política pressuposta nos conflitos sociais. É possível assim interpretar a esfera pública como o espaço social em que estão enraizados os diagnósticos dos bloqueios e potencialidades emancipatórias do presente. Junto às abordagens de uma teoria crítica sensível às tematizações do feminismo, defendo igualmente um conceito ampliado de práxis política que abarque a totalidade das relações sociais. Pois mesmo se contássemos com instituições legalmente estáveis e bem avaliadas do ponto de vista da democracia política, não seria possível afirmar que vivemos de fato em uma sociedade democrática se continuamos convivendo com experiências sociais sexistas ou outros tipos de violação social da autonomia. Ter autonomia significa não se submeter à dominação, discriminação, desrespeito e violência nos diversos contextos sociais da vida. Implica, portanto, poder se autogovernar (ou seja, a capacidade de se autorrealizar e se autodeterminar) no cotidiano de suas interações sociais (MELO, 2017). As demandas feministas apontam para este grau de aprofundamento da liberdade e respeito mútuo em todos os âmbitos da cultura política: tanto na esfera pública quanto nas dimensões privadas, as lutas das mulheres contra a subordinação de gênero estão tornando possível, por um lado, o reconhecimento da centralidade do diagnóstico acerca da dominação social que as afeta e, por outro, a importância em renegociar e politizar crítica e radicalmente, no projeto emancipatório de nossas ainda frágeis democracias, os padrões, estereótipos e atitudes sexistas vigentes.

\section{NOTAS}




\footnotetext{
${ }^{1}$ Doutor em Filosofia pela Universidade de São Paulo (Usp). Professor do Departamento de Ciência Política da USP e pesquisador do CEBRAP.
}

${ }^{2}$ No que diz respeito à relação entre feminismo e os temas centrais da teoria política, cf. especialmente Biroli e Miguel, 2014.

3 Não devemos perder de vista as diferenças entre as obras já consolidadas destas três autoras. Para uma discussão inicial sobre a especificidade de seus modelos críticos, cf. Silva, 2008.

${ }^{4}$ Raça, sexualidade e posição de classe também iluminam, por sua vez, as condições precárias das mulheres. Não se trata, portanto, de afirmar que uma perspectiva seria mais central do que a outra, mas apenas dizer que a dominação se manifesta de forma diversa e interseccionada nas relações sociais. A teoria crítica feminista foi capaz de compreender esse tipo de complexidade nos seus diagnósticos. Sobre experiências interseccionais de dominação, cf. Davis (2016) e Kerner (2012). Ver em especial o debate iniciado pela proposta de Fraser ao pensar as diferenças e relações entre injustiça material e cultural a partir da distinção entre "redistribuição" e "reconhecimento" (FRASER, 1997a).

${ }^{5}$ Veja, por exemplo, as considerações de Jean Cohen ao dizer que a centralidade do diagnóstico da opressão de classe e a da luta proletária revolucionária deixou de lado a experiência vivida pelas mulheres, excluindo perigosamente a possibilidade de "haver outros modos de dominação que não as relações de classe socioeconômicas" (COHEN, 1982, p. 193). Outro exemplo paradigmático se encontra em uma das primeiras formulações da crítica de Fraser à tese habermasiana da colonização do mundo da vida pelos sistemas da economia e do poder burocrático. Segundo a autora, Habermas não foi capaz de diagnosticar as patologias do capitalismo tardio porque não teria incluído a perspectiva de gênero (FRASER, 1989). Por seu turno, a dominação sofrida pelas mulheres orientaria melhor o diagnóstico geral das economias pós-liberais.

${ }^{6}$ A própria Fraser reviu sua posição. Se antes a teoria apenas esclarecia as aspirações dos movimentos, sobretudo do feminismo, agora caberia à teoria, caso necessário e dependendo do diagnóstico, distanciamento para elaborar uma crítica ao próprio movimento social. Foi o que fez Fraser ao criticar mais recentemente a terceira onda do movimento feminista a partir de seu diagnóstico do capitalismo globalizado e das ambiguidades das conquistas políticas obtidas no período, de um lado, e de seu princípio normativo da "paridade de participação", de outro (Fraser, 2013, Parte III).

7 A coletânea mais importante sobre o livro é sem dúvida a de Calhoun (1992). Para uma discussão sobre o livro e seu estatuto na obra posterior de Habermas, cf. Johnson (2006) e Melo (2015, 2016). A outra exposição significativa em sua obra do conceito de esfera pública aparecerá somente em Habermas (1994), em que vários aspectos foram totalmente reelaborados, principalmente ao incorporar boa parte das críticas das feministas.

${ }^{8}$ Não quero com isto afirmar que foi a primeira autora a tratar da questão de gênero na literatura histórica e política. A própria Landes reconhece a importância de várias autoras antes dela, com destaque para Wollstonecraft (2016).

${ }^{9}$ Com grande impacto, por exemplo, no tema da exclusão de gênero e na formação de uma cultura política na Europa (ELEY,1992), na construção de espaços de convivência e sociabilidade das mulheres americanas na luta por direitos iguais (RYAN, 1992; BOYTE e EVANS, 1992), na visão das experiências de racismo e subordinação de mulheres negras nos EUA (BROOKS-HIGGINBOTHAM, 1993).

10 Sigo em alguma medida nesta reconstrução os argumentos inicialmente defendidos em meu texto programático sobre teoria crítica e esfera pública, que foi publicado em Melo, 2015.

${ }^{11}$ Carole Pateman ilustra da seguinte maneira a visão liberal tradicional: “A família é baseada em laços naturais de sentimento e de sangue, e na condição sexualmente definida de esposa e marido (mão e pai). A participação na esfera pública é regida por critérios universais, impessoais e convencionais de êxitos, interesses, direitos, igualdade e propriedade - critérios aplicáveis apenas aos homens. Uma consequência importante desta concepção de público e privado é que, na teoria liberal (na verdade, em quase toda teoria política) conceitua-se e se discute o mundo público, ou a sociedade civil, abstraída ou separada da esfera privada doméstica" (PATEMAN, 2013, p. 59).

${ }^{12}$ Para a teoria da circulação do poder na esfera pública, cf. Habermas (1994) e Melo (2015).

\section{REFERÊNCIAS BIBILIOGRÁFICAS}

BENHABIB, S. "Models of Public Space: Hannah Arendt, the Liberal Tradition and Jürgen Habermas". In: Benhabib, S. Situating the Self: Gender, Community and Postmodernism in Contemporary Ethics. New York/Routledge, 1992a. 
. "The Generalized and the Concrete Other". In: Benhabib, S. Situating the Self: Gender, Community and Postmodernism in Contemporary Ethics. New York/Routledge, 1992b.

. "Sobre um modelo deliberativo de legitimidade democrática". In: Melo, R.; Werle, D. L. (orgs.). Democracia deliberativa. São Paulo: Esfera Pública, 2007.

BIROLI, F. e MIGUEL, L. F. Feminismo e política. São Paulo: Boitempo, 2014.

BOYTE, H.; EVANS, S. Free Spaces: The Sources of Democratic Change in America. Chicago: University of Chicago Press, 1992.

BROOKS-HIGGINBOTHAM, E. Righteous Discontent: The Women's Movement in the Black Baptist Church, 1880-1920. Cambridge: Cambridge University Press, 1993.

CALHOUN, C. The Question of Class Struggle: Social Foundations of Popular Radicalism in Industrial England. Chicago: The University of Chicago Press, 1982.

CALHOUN, C. (org.). Habermas and the Public Sphere. Cambridge/London: MIT Press, 1992.

COHEN, J. Class and Civil Society: The Limits of Marxian Critical Theory. University of Massachusetts Press, 1982.

DAVIS, A. Mulheres, raça e classe. São Paulo: Boitempo, 2016.

ELEY, G. "Nations, Publics, and Political Cultures: Placing Habermas in the Nineteenth Century". In: Calhoun, C. (org.). Habermas and the Public Sphere. Cambridge/London: MIT Press, 1992.

FRASER, J. "What's Critical about Critical Theory? The Case of Habermas and Gender". In: Fraser, N. Unruly Practices: Power, Discourse and Gender in Contemporary Social Theory. Minneapolis: University of Minnesota Press, 1989.

. "From Redistribution to Recognition? Dilemmas of Justice in a 'Postsocialist' Age”. In: Fraser, N. Justice Interruptus. New York/London: Routledge, 1997a.

. "Rethinking the Public Sphere: A Contrbution to the Critique of Actually Existing Democracy". In: Fraser, N. Justice Interruptus. New York/London: Routledge, 1997b.

Fortunes of Feminism: From State-Managed Capitalism to Neoliberal Crisis. New York/London: Verso, 2013.

HABERMAS, J. Faktizität und Geltung. Frankfurt am Main: Suhrkamp, 1994. . Mudança estrutural da esfera pública. São Paulo: Unesp, 2014.

HORKHEIMER, M. “Traditionelle und kritische Theorie". In: Horkheimer, M. Gesammelte Schriften. Bd. 4. Frankfurt am Main: Fischer, 2009.

JOHNSON, P. Habermas: Rescuing the Public Sphere. New York/London: Routledge, 2006.

KERNER, I. "Tudo é interseccional? Sobre a relação entre racismo e sexismo". Novos Estudos CEBRAP, 93, 2012. 
KLUGE, A.; NEGT, O. Public Sphere and Experience: Toward an Analysis of the Bourgeois and Proletarian Public Sphere. Minneapolis: University of Minnesota Press, 1993.

LANDES, J. Women and the Public Sphere in the Age of the French Revolution. Ithaca/London: Cornell University Press, 1988.

MELO, R. Marx e Habermas: teoria crítica e os sentidos da emancipação. São Paulo: Saraiva, 2013.

Nova, 94, 2015.

"Repensando a esfera pública: Esboço de uma teoria crítica da democracia". Lua

- "Discursos práticos e esfera pública: Sobre as críticas de Thomas McCarthy a Jürgen Habermas”. Ideias. 7, 2016.

. "A soberania popular revisitada: Autogoverno como modo de vida". Cadernos de filosofia alemã: Crítica e modernidade. 22, 2017.

NOBRE, M. A teoria crítica. Rio de Janeiro: Jorge Zahar, 2004.

NOBRE, M. (org.). Curso livre de teoria crítica. Campinas: Papirus, 2008.

PATEMAN, C. "Críticas feministas à dicotomia público/privado". In: Biroli, F.; Miguel, L. F. (orgs.). Teoria política feminista: textos centrais. Vinhedo: Editora Horizonte, 2013.

RYAN, M. "Gender and Public Access: Women's Politics in Ninetheenth-Century America". In: Calhoun, C. (org.). Habermas and the Public Sphere. Cambridge/London: MIT Press, 1992.

SILVA, F. G. "Iris Young, Nancy Fraser e Seyla Benhabib: uma disputa entre modelos críticos”. In: Nobre, M. (org.). Curso livre de teoria crítica. Campinas: Papirus, 2008.

WOLLSTONECRAFT, M. Reivindicação dos direitos da mulher. São Paulo: Boitempo, 2016.

YOUNG, I. Justice and the Politics of Difference. Princeton: Princeton University Press, 1990.

"Comunicação e o outro: Além da democracia deliberativa". In: Souza, J. (org.). Democracia hoje: Novos desafios para a teoria democrática contemporânea. Brasília: UnB, 2001. 